\title{
Analyses and Countermeasures for the Implementation of the Social Insurance Law
}

\author{
Ma Bin ${ }^{1}$ \\ ${ }^{1}$ Xi’an International University, 710077
}

Keywords: Social Insurance Law, Implementation, Countermeasure

\begin{abstract}
Nowadays, the thinking of making laws for the people and ruling the country according to laws is deeply planted among the people, and the construction of socialism with Chinese characteristics needs the construction of legislation of socialism with Chinese characteristics as well. The development and improvement of legislation, which the perfection and improvement of legislation are according to, is aim for the benefit of people firstly, and ensuring the rights of people. From the publishing of the Social Insurance Law to today, in one hand, it makes great progress on legislation, enlarges the scale of its benefiting, and improves the social security system. In other hand, it is clear that there is no the matching system that the rules of the law are not clear and the supervisions are missing. So the advantage and disadvantage of social security is clear. Therefore, in fact, there are many unreasonable and unscientific defects when the law is implementing, the law is not synchronous with reality, and it not only is far away from reaching the goal of scientific legislation, but also damages the benefit of people. According to some relevant materials, the author brings out the elementary countermeasures after researching some relevant materials.
\end{abstract}

To put the social security into laws is the way to safeguard the benefit of the citizen by compulsive legal method. It can improve the functions of the social insurance system and its credibility, and it is the expression of improving the legislation as well. The Social Insurance Law shows the key idea that to make laws for people by considering the benefit of people firstly, and protecting all the people's benefit. It is a kind of improvement on legislation.

\section{Significance of the Social Insurance Law}

China's legal system is not perfect, and has been in the process of development, the birth of the Social Insurance Law has fulfilled China's legal vacancy on social security system field, as it were, it is a law that could be remembered in history, is the important turning point of the legal perfection of China ${ }^{[1]}$. The publishing of the Social Insurance Law has changed the society of China from ruling by man to ruling by laws, has clarified the rights and obligations of every holder and every governmental department, and has clarified and subdivided the responsibilities of relevant units on social insurance field. From that time on, China had opened the curtain of legal times and entered the era of legislation ${ }^{[2]}$.

Before the Social Insurance Law is published, the public knew very little about this filed, so people lacked the awareness of pay the premium voluntarily and didn't know the functions of social insurance; many people do not care about social insurance. Therefore, it is lack of popularity on social insurance in some extent. The publication of the Social Insurance Low increases the popularity of social insurance by legal and compulsive way. It not only fulfills the gap of the legislation, but also ensures the benefit of the public by the special compulsive way; it not only is the necessary step for building the humorous society, but also the important measure of regulating the system. The publication of the Social Insurance Law builds a steady security regime which could work smoothly, and consolidates the base of the humorous society which will become stronger and steadier.

The Social Insurance Law comes from the public and it secures the public as well. It aims for protect the benefit of the public. Only the benefit of the public is secured, the public could devote themselves to the social construction. And then, China will become stronger. Legislation is the base 
of execution and practice for the Social Insurance Law, the law also improves the legislation conversely. The two factors promote each other and make progress together; this has important practical significance for the construction and strength of China. The basic objective of the Social Insurance Law is safeguarding the right of working people, arming the disadvantaged group, clearing the responsibilities and obligations of the employer and every worker who could has enough safeguards without anything to worry about ${ }^{[3]}$. As the main force of social construction, the worker is the key element of social progress, but, before the publication of the Social Insurance Law, their benefit could not be highlighted by the government and society. In fact, their benefit lacks security and their right lacks safeguard until the publication of the Social Insurance Law. The law breaks the awkward situation and let all the workers hold the strong right by the impulsive legal method.

\section{Problems in implementation of the Social Insurance Law}

It could not separate the ruling country by law from the construction of system and relevant regulations. It is a fantasy that any law could be popularized without the regulations of system. The construct of system depends on the law enforcement agencies ${ }^{[4]}$. The object of the Social Insurance Law is the whole labor class, is all the citizen namely, in some extent, the law has solved the problems such as the old problems and the medicine problems, etc, which secure the life of the citizen. But, the Social Insurance Law is published recently; there are still many limitations, loopholes and vacancies, therefore, there still are some obstacles during its implementation so that many rules of the law could not be operated. Many rules are too burdensome and repeated to implement, or are not fits the reality without matching system for cooperating with it, so the functions of the Social Insurance Law could not be revealed. It is this kind of lack on systematic supporting that many rules of the law become empty talk, so that the Social Insurance Law is hard to implement.

There are many indistinct parts in the rules of the Social Insurance Law, so that the responsibility and right can not be clearly divided. Take some rules of the endowment insurance for example: the government officer is more special than the common people in this field. There are an obvious different in the amount of premium between the both sides, but the officer own a higher rate of treatment than the others. This defect of the rules brings about many unfair phenomena ${ }^{[5]}$. There are lots of rigid uniformities in the rules without considering the difference between the different people, and the realistic conditions, this indistinct causes the unfair treatment during implementing that it seems fair. Take the migrant workers who is the majority of the population of Beijing, Shanghai, and Shenzhen for example, the treatments between those people are still different, this shows the defect of the Social Insurance Law more clearly.

At present, in the actual implementation of the Social Insurance law, because many regulations are not perfect and unclear, and the lack of supervision regime, there are many conflicts and contradictions in the implement. And the amount of people who pay the premium is too large, and that it involves too many units, many of the regulations can not be successfully executed in this complicated relationship and the complicated environment, and if it has been executed, it can not be executed well as well. Therefore, there are supervision problems and illegal executing problems, which emerge in large numbers. If there is no a strong supervision regime, the Social Insurance law will become a kind of decoration, and empty talk, its function will not be work, the benefit of the citizen will be losing. While the lack of supervision, many supervision units supervise badly, the lack of professional ability, and weak awareness of responsibility, resulting supervision failure, which makes the result of that the implementation of the Social Insurance Law is not satisfied.

\section{Countermeasures of the problems}

It is the working for constructing the legislation of grass-roots area well that the important means to keep a stable and harmonious society, that is the great push power to the legal and social idea of our country, and is the important step to implement the Scientific Thinking of Development at the 
some time. We should do a good job on the popularity and enforcement of legislation, and let every people has a good conception of legislation. However, to enforce the business of legislation, it must follow the Scientific Thinking of Development, combine the theory with the practice, analyze the realistic conditions in the grass-roots organizations and the public, popularize and improve the Social Insurance Low according to the realistic conditions. We should strive for the project that secures the grass-roots organizations and people, promote the construction of the legal society, and safeguard the benefit of every people.

The purpose of supervise is certain that the policy has been carried out well, that the Social Insurance Law could play an important role in our life. It needs the government to consider the Social Insurance Law seriously, to clear the responsibilities and obligations of their own, and to improve the current supervision regime. Only a systematic and scientific supervision regime could supervise the Social Insurance Low to be carried out smoothly; only enhancing the level of supervision could the implement of the Social Insurance Law meets the standard of it is expected. These needs to clear the responsibilities and obligations of the workers and relevant departments, which take part in the social security, build a supervision system which could clarify the right and obligation, let the public could take part in the system, which is formal, scientific, and participatory. At every stage of implementing the Social Insurance Law, every factor should be supervised. Let the workers to know their responsibilities, enhance their initiatives, and join to the supervision system on their own, enhance the supervision level, in order to implement the Social Insurance Law well.

On condition that without mending the Social Insurance Law, it should establish the reasonable regime of solving dispute by explaining and improving the relevant system. First, we should distinct the differences between the mediation of social insurance dispute and the mediation of labor dispute. Social insurance dispute mediation emphasize the dispute should be solved by means of "mediation by law", If there are some responsibilities should be undertaken by the employer, we should persuade the employer to undertake the duty which is statutory, but harm the employee's rights of social insurance. For the illegal and irrelevant questions bring out by the employee, we should mediate the problems by bring out the facts and reasons or by laws. Second, set up the social court which is specialized in the cases of social insurance. The social insurance disputes of our country are solved in the civil court or in the administrative court. It follows the civil or administrative procedure, ignores the essence and characteristics of the Social Insurance Law which is a kind of social laws. It not only breaks the inner regulations of social assistance, but also the effectively implement of the Social Insurance Law. Therefore, it is necessary to set up the special social court at all the courts for dealing with the social insurance case. For improving trial result, it is also necessary to build the special judgment team, which is well treated not only on laws but also on the social insurance major. ${ }^{[6]}$

\section{Conclusion}

As a great embodiment of Chinese featured legislation and a great landmark of legal perfection, the Social Insurance Law is realistic significant not only in legal theory but also in its implementation. The law really achieved that it considers the people's benefit firstly. The Law ensures the benefit of the most ordinary grassroots constructors and laborers, and becomes a legal weapon to ensure their benefit. But, in this time, because of many realistic reasons, there are many problems need to be solved urgently, it is a long road to walk on implementing the law. Therefore, the perfection of the Law needs all the public to do great contributions on it. Because of my limited knowledge and thinking about the law, I sincerely welcome all the specialists and scholars to point out the mistakes in this thesis so that the law will be improved and be implemented better and better. 


\section{Reference}

[1] Wang Liming. The problem of the Social Insurance Law of China and its countermeasures---Comment on the relative legal responsibilities of the 《Social Security Act(draft)》(draft for taking advices ) [J]. Nomocracy Forum,2009,04:68-87.

[2] Meng Tiancheng. Researching on the small-and-medium-sized enterprises' administration of human resources in the new legislation environment[D].Inner Mongolia University, 2013.

[3] Gao Guijun. Discussion on the challenges and countermeasures of the labor security supervision system during the Implementing of the 《Social Security Act》 [J].LAODONG BAOZHANG SHIJIE, 2011,11:50.

[4] Zhang Xiaoming, Zhou Tao, Pang Xiaofen. The analysis on realistic influence and countermeasure after implement the action of the 《Social Security Act》[J]. Shandong Human Resource and Social Security, 2011,12:26-27.

[5] Zhu Yinlin. Research on the implement problems and its countermeasures of the city and rural citizens[D]. South-central University for Nationalities, 2013.

[6] Xu Zhitao. Research on the mechanism of action and effect that how the endowment insurance adjust income distribution [D].Southwestern University of Finance and Economics, 2014. 